in-patient group programme for post-traumatic stress disorder (PTSD). Psychological debriefing is a term associated with Jeffrey Mitchell and Atle Dyregrov who each developed the technique to be used as an intervention for emergency workers shortly after a traumatic event to help prevent PTSD. We believe that to use this term for the treatment of established PTSDs, in some cases many years after the event, is confusing. It is clear that the programme includes a number of cognitive behavioural techniques including imaginal exposure which have been demonstrated to be effective in PTSD.

No one has as yet established that techniques based on the models of Mitchell and Dyregrov are effective in the treatment of PTSD (Raphael et al, 1995). Indeed, there are reports of the psychological debriefing process in its proper context increasing rather than decreasing subsequent morbidity (Deahl et al, 1994). The basic assumption, therefore, that psychological debriefing works, is in our view unsafe and to extend it in the way such as has been postulated by Busuttil et al (1995) serves only to add to the ever increasing fog that surrounds the whole area of traumatic stress and its treatment.

Busuttil, W., Turnbull G. J., Neal, L. A., et al (1995) Incorporating psychological debriefing techniques within a brief group psychotherapy programme for the treatment of posttraumatic stress disorder. British Journal of Psychiatry. 167, 495-503.

Deahl, M. P., Gillham, A. B., Thomas, J., et al (1994) Psychological sequelae following the Gulf War: factors associated with subsequent morbidity and the effectiveness of psychological debriefing. British Journal of Psychiatry, 165, 60-65.

Raphael, B., Meldrum, et al (1995) Does debriefing after psychological trauma work? British Medical Journal, 310, 1478-1479.

Duchess of Kent's Military Hospital

M. LEIGH-HOWARTH M. R. BAGGaLeY

Horne Road

Catterick Garrison

North Yorkshire DL9 4DF

\section{Brief psychotic episodes in puberty}

SIR: Abe \& Ohta's report of brief psychotic episodes in puberty (1995) is seriously flawed.

The sample was small and included significant confounding aetiologies; Prader-Willi Syndrome, current neuroleptic treatment and an EEG suggesting epilepsy. Similarly, mental retardation was not considered an exclusion criterion. Symptoms suggested as characteristic of this group are poorly defined, e.g. "jitters", or possibly unrelated to psychopathology (pallor and enuresis). That none of the cases met ICD-10 durational criteria for 'recurrent depressive episode' is not remarkable when symptoms lasting beyond 15 days led to exclusion from the study. Also, insomnia which may have marked the onset of illness was considered to have preceded it in some cases, artificially lowering the episodes' recorded duration.

Omitting laboratory screening for illicit drugs and indicators of alcohol abuse invalidates a study of brief psychotic illness, particularly in an adolescent population. Ascribing successful outcome to sulpiride or lithium is questionable as by definition subjects had illnesses which remitted within 15 days without treatment.

This paper suggests that these individuals with similar symptomatology represent a single syndrome or diagnosis. There are however numerous aetiological possibilities and potential diagnoses in this very heterogeneous group.

ABE, K. \& OHTA, M. (1995) Recurrent brief episodes with psychotic features in adolescence: periodic psychosis of puberty revisited. British Journal of Psychiatry, 167, 507-513.

Cutring, J. C., Clare, A. W. \& ManN, A. H. (1978) Cycloid psychosis - An investigation of the diagnostic concept. Psychological Medicine, 8, 637-648.

Brockington, I. F., Perris, C., Kendell, R. E., et al (1982) The course and outcome of cycloid psychosis. Psychological Medicine, 12, 97-105.

A. LLoYd

Child and Family Psychiatry Unit

J. MCDonald

Queen Elizabeth Hospital

Tyne And Wear NE9 6SX

\section{Non-Alzheimer dementias in young patients}

SIR: We feel that both Williams (1995) in his editorial and Newens et al (1995) in their paper have to some extent missed one of the major characteristics of the population of younger dementia sufferers. Both authors have concentrated on Alzheimer's disease (AD), and have not considered patients with non-Alzheimer dementias.

In our experience of providing both a local and national referral service for younger people with dementia, only a half of demented patients under the age of 65 years have $\mathrm{AD}$. In a recent audit of 283 patients seen in our clinic, 261 were confirmed as having a progressive dementia, of which only 130 fulfilled clinical criteria for Alzheimer's disease. Seventy-one patients were found to have an asymmetric focal cortical atrophy associated with clinical diagnoses of Pick's disease, frontal lobe 
degeneration, primary progressive aphasia and corticobasal degeneration.

Caring for any patient is stressful, but carers of younger dementia sufferers, who often have to abandon employment to provide care, are particularly affected. Many carers are helped by joining carers groups. In the case of a carer looking after someone with a non-Alzheimer dementia, the experience of AD carers may be of limited relevance as their practical problems are quite different. Providing the family and carers with the correct diagnosis and explanation of the disease can be very beneficial and may open the door to specific support services such as The Pick's Disease Support Group.

As Williams (1995) recognises, planning comprehensive services for this group of patients on a local basis is problematic, especially given the heterogeneity of the clinical picture, and the difficulty of making the diagnosis in many cases. We have responded to this challenge by starting a novel service called CANDID (Counselling and Diagnosis in Dementia). This provides information, education and advice by telephone and the Internet to support professionals and families who are looking after a younger person with dementia. The feedback of specialist advice through the GP, hospital consultant and local services is proving to be particularly valuable for this group. The service is under close evaluation but may offer a model for providing coordinated care to the estimated 20-30000 younger sufferers of dementia in the UK.

The Pick's Disease Support Group and CANDID can be contacted via Penelope Roques.

Newens, A. J., Forster, D. P. \& Kay, D. W. (1995) Dependency and community care in presenile Alzheimer's disease. British Journal of Psychiatry, 166, 777-782.

Williams, D. D. R. (1995) Services for younger sufferers of Alzheimer's disease. British Journal of Psychiatry, 166, 699-700.

R. J. HARVEY

P. ROQUES

N. C. Fox

The National Hospital for Neurology

M. N. Rossor

and Neurosurgery

Queen Square

London WC1N $3 B G$

e-mail: candid-dementia-request@mailbase.ac.uk World Wide Web:

http://www.ion.bpmf.ac.uk/ rharvey/candid.html
Quality of statistics in psychiatric research

SIR: The level of statistical errors as revealed by McGuigan (1995) in the British Journal of Psychiatry during 1993 is obviously disturbing. Furthermore it is of great concern that this rate has not effectively reduced since the study of White (1979). However, I find such studies can be difficult to interpret in real terms. This is not least because what constitutes a statistical error can be purely subjective (Hand \& Sham, 1995). It is the severity ofany error, although also subjective in itself, rather than the number of errors per se that is of greater interest.

The medical literature is repeatedly trying to increase researchers' knowledge of statistics. I am concerned as a professional statistician that this is seen by many as providing the competency in the execution, rather than an education in the appreciation, of statistics. Statistics is a science that demands proper training. An increase in readily accessible computer software has also unfortunately encouraged individuals to develop the "have a go approach'. In combination, these factors have contributed significantly to the present situation concerning the quality of statistics in medical journals. The main stumbling block as I see it is the lack of qualified statisticians and not until this issue is rectified will there be improvement. In particular it will facilitate the appointment to journals of professional statisticians as referees where typically there are few, if any, at present. This need is urgent since when one stops to consider the errors cited by both McGuigan (1995) and White (1979), one surely has to question the validity of research that has gone beforehand.

HAND, D. \& SHAM, P. (1995) Improving the quality of statistics in psychiatric research. British Journal of Psychiatry. 167, 689-691.

McGuigan, S. M. (1995) The use of statistics in the British Journal of Psychiatry. British Journal of Psychiatry, 167, 683-688.

WhITE, S. J. (1979) Statistical errors in papers in the British Journal of Psychiatry. British Journal of Psychiatry, 135, 336-342.

St. George's Hospital Medical School

P. SEDGWICK

Cranmer Terrace

London SW17 ORE 